\title{
Research on Employee Pressure and Resistance Caused by Organizational Change-A Case Study of Jingyi Network Co., Ltd.
}

\author{
Yangyu Zhang \\ School of Management, Shanghai University, Shanghai, China \\ Email: kellyboy@shu.edu.cn
}

How to cite this paper: Zhang, Y.Y. (2019) Research on Employee Pressure and Resistance Caused by Organizational Change-A Case Study of Jingyi Network Co., Ltd. Open Journal of Social Sciences, 7, 72-85. https://doi.org/10.4236/jss.2019.75005

Received: April 6, 2019

Accepted: May 5, 2019

Published: May 8, 2019

Copyright (อ 2019 by author(s) and Scientific Research Publishing Inc. This work is licensed under the Creative Commons Attribution International License (CC BY 4.0).

http://creativecommons.org/licenses/by/4.0/

\section{(c) (i) Open Access}

\begin{abstract}
According to the theory of organizational change, this paper takes Jing Yi Network Technology Co., Ltd. as an example to analyze the problem of employee pressure and employee resistance caused by organizational change. In order to more comprehensively discuss the causes of employee pressure and resistance under organizational change, the impact of employee pressure and resistance on enterprise development, and the countermeasures to reduce the pressure and resistance of employees, it is carried out from four aspects: organizational structure change, organizational personnel change, organizational technology change and organizational culture change. Finally, some suggestions and future prospects are put forward.
\end{abstract}

\section{Keywords}

Organizational Change, Employee Pressure, Employee Resistance

\section{Introduction}

With the emergence of related concepts such as organization, the related research of organizational reform and change keep emerging. For example, Nigam, et al. (2016) believe that organizational change is a progressive process as well as a dynamic development process, they also summarize that research with organizational change mainly focuses on the background, type, main content, development trend, as well as employee pressure and resistance to change brought by organizational change [1]. Furthermore, research on the pressure and resistance of employees brought by organizational change is mainly reflected in the following aspects: 1) Taking the source of the factors hindering the change as the research objects, Chen et al. (2015) believe that senior managers 
have the most serious influence on organizational change in enterprises [2], while Stephen and Mary (2013) believe that the hindering factors mainly include personal factors and social factors [3]. 2) Studies on different types of resistance. Stephen P. Robbins has pointed out that the type of resistance to change depends on the field in which it occurs. 3) Research on methods to reduce resistance to change. Many scholars proposed six solutions of participation, simplification, negotiation, communication, control and compulsion (Gersick, 1991; Stephen and Mary, 2013) [3] [4]. Based on this, Colin (2015) further proposed six solutions of education, communication, participation, promotion, support, negotiation and compulsion [5]. Change is a dynamic process of change. According to the changes of the external environment, organizations adjust themselves to adapt to the external environment and internal changes, so as to achieve long-term development of the organization. Therefore, the research on organizational change is also in constant development and change. Due to the large scale of Jingyi Network Technology Co., Ltd., the scope of organizational change has been relatively large in recent years. In addition, through my research, it is found that the pressure and resistance of Jing Yi employees in organizational change is a common phenomenon in many enterprises with wide applicability. Therefore, this paper takes Jing Yi Network Co., Ltd. as an example to analyze the pressure and resistance of employees under organizational change in a more specific way.

\section{A Review of Studies on Employee Pressure and Resistance Caused by Organizational Change}

With the emergence of related concepts such as organization, the related research of organizational reform and change keep emerging. Through literature review, it is found that existing studies on organizational change mainly focus on the connotation, motivation, content and dimension of organizational change, as well as the process and influencing factors of organizational change.

\subsection{Connotation of Organizational Change}

For organizational change, different scholars have different understanding and views, so there is no clear unified definition in the academic world. Lindel (1979) believes that organizational change is a series of optimization activities and processes carried out by an organization to coordinate with its internal and external environment [6]. Meng Fanxiang et al. (2008) proposed that organizational change is a dynamic process that develops continuously with the external environment [7]. Zhang Yongsheng (2008) also believes that organizational change is a systematic project, which mainly includes the change of organizational members, organizational structure and organizational technology and tasks [8]. Based on the previous discussion, this paper argues that organizational change as a dynamic process of organizations adjust themselves to adapt to the external environment and internal changes, so as to achieve long-term develop- 
ment of the organization, it mainly includes changes in organizational technology, structure, personnel and culture.

\subsection{Related Research Employee Pressure and Resistance Caused by Organizational Change}

With the increasing number of studies on organizational change, the research on the influencing factors of organizational change has attracted more and more attention from scholars. For the research on influencing factors, most scholars focus on the hindrance of employees to organizational change. Di Yang (1998) found that organizational members resisted the introduction of new technologies, management path dependence resisted changes, employees were afraid of uncertainty and failure, and individual interests and overall interests were not coordinated [9]. Based on DiYang (1998) study, Qi Zhenhong (2008) put forward further hinder organizational change are the major factors of employees' fear and doubt, vested interests do not want to lose interest, uncertainty, group pressure and refuse to be constraints [10], in addition, there are some scholars think that organizational culture will also hinder the consistency of the organizational change (Graetz et al., 2010; Chen Geng et al., 2011) [11] [12]. Therefore, this paper will also analyze the pressure and resistance of employees in Jingyi Network Technology Co., Ltd. from the above aspects.

\section{The Status Quo of Organizational Change in Jing Yi}

Jing Yi, founded in 2005, is a large classifieds site, called the Shanghai Jing Yi Network Technology Co., LTD., its business scope includes: dealer services, real estate, recruitment and service, According to the official website of Jing Yi Network Technology Co., LTD., now the customer more than one hundred million people, new information as many as ten million per month, 367 key cities all over the country, in the current classification information website competitive circumstances, it is necessary to constantly carry out organizational changes and improve their competitive advantages. Since organizational change includes changes in organizational technology, structure, personnel and culture, this paper will carry out research from these four aspects.

\subsection{Technological Change}

The technical changes in Jing Yi can be divided into three main categories. The first is the replacement of equipment. When the company was founded in 2005, due to the shortage of funds, the office equipment was relatively simple at that time. Dozens of square meters of office space, a couple of 20 employees had several old computers, and all relied on manual work, the workflow is time-consuming and inefficient, through continuous organizational changes, the company implemented office computerization and work automation, so that each employee has a new version of desktop computer. Each computer is equipped with a landline phone, and each employee has his own desk and office 
equipment.

The second is the change of working mode and working environment. From the initial paper-based office, the staff searched for resources on their own, transformed into computer-based office, and established the customer pool of the whole company. From the original direct door-to-door visit, the staff transformed into telephone call first to find out the intention of the customers, and then visited the company through the address provided by the customers on their own initiative. The working time has changed from the original 10-hour system to the present one with five days off and two eight-hour working days. The working environment has also changed from the original dozens of square meters to hundreds of square meters. The office area of corresponding departments and the independent office environment of corresponding leaders have been set up, which has improved the external competitiveness and competitive advantage of the company.

The third is the improvement of employees' knowledge and skills. Due to the change of working mode and equipment, employees must have the corresponding working ability. Through the training of the required ability of employees, employees need to master a variety of skills instead of the basic business ability, which increases the work efficiency of employees. It also increases the profitability of the enterprise.

\subsection{Organizational Structure Change}

\section{Functions and Powers}

Organizational structure change mainly includes two aspects. First, changes in functions and powers. When Jing Yi was just established, the boundaries between departments were not clear and the functions of employees overlapped, so the individual work of employees was not very clear. As a result, the work efficiency of the enterprise is low. The company changes its organizational structure by setting up a linear functional system, which makes employees have clear rights and responsibilities and significantly improves their work efficiency. The change of the management power of the fine network is very obvious. The original system is centralized. The general manager makes decisions independently without consulting the staff, so the flow of power is unidirectional, from top to bottom. Now is distributed to the employee's work gives greater authority, the reform of the general manager and staff communication company, gives power to the corresponding staff, through employee feedback regularly, and get to know work condition, the power to make the development of the company below and dispersion is no longer a person to make a decision, but to make employees to participate in, to provide more decision-making and development, but also improve the staff's organizational commitment, enhance the enterprise's innovation ability and business activity.

Second, changes in departments and levels. The expansion of the company, will inevitably lead to the changes in the amplitude of the hierarchy and man- 
agement, refined from the original single organization structure of the two layers, the development for a more complete more hierarchical chain of command, from the original business, no department to now according to the company's main products are divided into four major departments, is divided into four large dealer, recruitment, real estate, and the service, each big department is equipped with the personnel, financial and other functional departments, and each big department in every year, every month have a specific goal, have corresponding rewards and punishment system, department of subdivided make business more regularized.

\subsection{Personnel Change}

Personnel change can be mainly divided into three aspects. The first is a change in staff attitudes. With the change of salary performance and incentive policy, the working attitude of employees in Jing $\mathrm{Yi}$ is constantly changing, because the original no matter what job to do, is to receive a fixed salary every month, lead to employees working hours just want to complete the company's rules, and most of the employees working, the overall working efficiency is lower, the atmosphere is depressed, the relationship between employees and managers is like cat and mouse, work or not work completely on the supervision of the manager, so invisible increased the workload of administrators, also encourages the employees slacking psychology, with the continuous development of organizational change, the company formulated the corresponding incentive mechanism. The policy of increasing basic salary and commission has changed the working attitude of employees. Employees are not only willing to work overtime, but even ask to work overtime, which has increased the operating efficiency and efficiency of the company.

The second is the change of employee expectation, cognition and behavior. Employees' expectations and cognition of the enterprise determine their attitude towards work and indirectly determine the degree of achievement of enterprise goals, so Jing Yi have recognized this problem at a very early age, and fundamentally educate and train employees so that they have the right attitude, so as to achieve the long-term development of the enterprise. In addition, Jing Yi enables employees to have positive behaviors through educational communication and mutual supervision and help among employees.

The second is the change of personnel promotion system and salary performance appraisal system. The promotion system of precision is changed from the original position vacancy of the company to the promotion based on the seniority of employees, and then to the promotion based on performance that is evaluated every two months. If you meet your goals in two months, you can move up a level in the third month. For the promotion space from S1 to S10, if the employee is promoted to $S 10$, he can apply to be a manager and lead the team by himself. This kind of change has virtually accelerated the development of the company, but at the same time, it has changed a lot of aspects of the company. 


\subsection{Cultural Change}

The change of corporate culture is mainly reflected in the company's beliefs and values. Every Monday, the company holds an early morning meeting for all the employees. In each meeting, the company's belief is read out, so as to establish the value system of the company. Jing Yi has been advocating employees to learn “yangming mind learning". It is Wang Yangming's work and a state of mind when facing difficulties. Jing Yi uses it to motivate employees for changing the mentality of employees to work, so that employees can face the trough of the work with an optimistic attitude, thus employees better work for the company. In addition, it also includes some changes in cultural characteristics. The company's culture includes material culture and spiritual culture. In the company's material culture, in the form of weekly banner changes, there are visible signs in conference rooms, lobbies, and even on employees' workstations, with monthly and quarterly targets, as well as the development of competitors. In the company's spiritual culture, The company plays motivational music every morning to keep employees energized, before going to work in the afternoon, the part of playing games was added to make employees have a positive mental state to enter the work and improve the work efficiency of employees. Through the dual changes of spiritual culture and material culture, employees' satisfaction with the company has been significantly improved.

\section{Employee Pressure and Resistance Analysis}

\subsection{Sources of Stress}

\subsubsection{Employee Pressure under Personnel Change}

First, the company promotion space increases, causes the company interior competition to become more intense. Employees are eager to have their efforts rewarded, but after all, the company's promotion is limited, which increases the psychological pressure of employees. Schwarz and Stensaker (2016) put forward that with the development of the times and economy, employees have greater psychological expectations for their salary and power, which strengthens the psychological comparison among employees, making the pressure of employees more unbearable [13].

Second, because of the special promotion system, the subordinate can immediately become his or her own level or superior, so the relationship between the leader and the led will change. Liu jia (2017) believes the way people get along with each other has changed, which inevitably brings about changes in the interpersonal relationship and pressure on employees [14].

Finally, Personnel change leads to continuous changes in the leadership team of the company. Rolf and Valeria et al. (2018) put forward each leader's strategic approach, leadership style, and requirements for employees are different, employees need to adjust their state to face the changing leadership style at any time, and the pressure brought by this cannot be ignored [15]. 


\subsubsection{Employee Pressure under Organizational Structure Change}

The change of business direction may change the development process of the enterprise. The strategy of an enterprise is the guide for the development of the enterprise. Richardson et al. (2017) believes that the change of strategy will lead to the change of the middle-level and grass-roots operations of the enterprise, which requires the cooperation and coordination of all the employees of the enterprise, thus bringing certain pressure to the employees [16].

The change of enterprise management level and range is a great challenge for both enterprise managers and ordinary employees. There is a close relationship between management level and range. Management range refers to the number of employees directly managed by a manager, while management level refers to the number of managers in an enterprise. The larger the range is, the smaller the management level will be. Castillo and Fernandez et al. think a mature management model is that the organization tends to be flat [17]. For managers, no matter how big the range of management, they need to effectively manage employees, for employees, they need to cooperate with managers and coordinate all aspects. So, there is a certain pressure on both managers and ordinary employees.

\subsubsection{Employee Pressure under Technological Change}

Colin puts forward that enterprise technological change requires certain knowledge and skills of employees [5]. For Jing Yi, with the implementation of office automation and computerization, employees are required to skillfully master the corresponding skills, knowledge and corresponding business ability of computers, but this is very difficult for employees who seldom contact with computers, In addition, the company has added a new landline phone connected to the computer, so a series of operations for the staff to learn again, will inevitably bring some pressure to the staff.

Jing Yi has transformed the office space, and the current workplace is relatively open without the original independent office, and some new office equipment has been added to change the corresponding working methods. American Project Management Association put forwards that employees need to adapt to the new environment and methods, and change the work mode they are used to, which increases pressure [18].

\subsubsection{Pressure of Employees under the Change of Corporate Culture}

The enterprise propagates Yangmming mind-learning, which will change the staff's view to some originally familiar things. It is a long process to accept new culture and values, which requires the joint efforts of all employees in the enterprise and will bring pressure to employees.

\subsection{Sources of Resistance}

Employee resistance mainly comes from three aspects. The first is employees' uncertainty about personal gains and losses. Organizational change is an uncer- 
tain process, and employees are not sure what kind of results will be brought to them after organizational change. Therefore, I will doubt the decision made by the company and think that the original stable state is familiar to me. I don't want to start all over again after the change. Uncertain things always make people worry and afraid, so employees would rather maintain the stability of the status quo, rather than carry out a change with uncertain results. Demotion and lay-offs are also among the most common concerns of employees, in order to avoid similar situations, employees will try their best to prevent organizational changes.

Second, employees are reluctant to change their habits. Zhang Jing and Duan Yanling (2013) believe one reason to resist change is that we all do things by habit. Life is complicated, and we don't want to make hundreds of decisions every day to consider all the alternatives [19]. Just as employees of Jingyi have been used to the current working mode, they are used to the original working mode and the habit of working together, as well as the company's performance appraisal system and reward and punishment system, so the daily work planning has become a habit. In addition, the relationship between colleagues is also established and has reached the corresponding balance in all aspects and the working state of employees' habits. Of course, they do not want to change. So, the instinctive tendency to react can be a source of resistance to change.

The last reason for resistance to change is the belief that change is incompatible with organizational goals and interests (Zhang Jie and Fan Yun, et al., 2013) [20]. At present, the enterprise has reached a stable state, and its profitability and competitiveness have both reached a stable state. Once it is broken, it may have a bad impact, resulting in the decline of the profitability of the organization, the disappearance of the competitive advantage in operation, and the corresponding reduction of what employees can get from the organization. Employees worry about personal gain and loss, so they block change.

\subsection{The Disadvantages of Employee Pressure and Resistance on Organizational Change}

The disadvantages are mainly reflected in four aspects. First, employees are inactive. Appropriate pressure will have a positive effect, but excessive pressure will have a negative effect, and employees will be anxious and upset, so that employees will be inactive (Lin Zhong, Zheng Shilin, Xia Fubin, Meng Defang, 2016) [21]. For example, many employees will use the company's software to chat and call their friends. Some employees will sit there and spend hours on their work. Their work efficiency is generally low. The investigation found that inappropriate organizational changes caused excessive pressure on employees.

Second, the difficulty of business management increases. Employees hinder organizational change, which will bring some troubles to managers. Each employee has his own ideas, and there are many ways to block the change, which is a big challenge for management. Maggie Farrell (2018) puts forward that how to 
deal with the relationship between employees and the enterprise, how to adjust employees' emotions and guide their behaviors are all issues that managers need to consider, which greatly increases the difficulty of enterprise management [22].

Third, it hinders the formulation of corporate policies. The ways in which employees are impeding change, most importantly, are impeding the formulation of company policies. Zhang Jie, Fan Yun and Zhang Xu (2016) believe that organizational change mainly promotes the continuous development of the organization through the formulation of new policies, and the negative impact of employee pressure and resistance on the company's policy making is fatal [23]. Company policies cannot be formulated and implemented effectively, which will greatly reduce the operating efficiency of the company, not only reducing the short-term benefits of the company, but also hindering the long-term development of the organization.

Finally, it is not conducive to the organization to integrate technologies and resources. The external environment of the enterprise has changed and the strategic adjustment of the organization makes the organization need to carry out organizational change. Enterprises need to integrate existing technologies and resources to adapt to the change of internal and external environment of enterprises and the adjustment of strategies. Shi Guangwen (2019) also believes that Employees' hindrance to organizational reform is actually equivalent to hindering the integration of corporate resources and technologies to some extent [24].

\subsection{Solutions to Employee Stress and Resistance Reduction}

\subsubsection{Ways to Reduce Employee Stress}

Through analysis, this paper proposes four methods to reduce the pressure on employees. First, the employee consults and sets reasonable and clear objectives. Employee consultation is to let employees have a certain understanding of organizational change, so as to realize the importance of organizational change. Through talking with employees, employees can dispel their concerns about organizational change. James H. (2017) Points out that by understanding employees' inadaptability to organizational change, we can help employees solve the problems they are facing and reduce their pressure on organizational change [25]. Setting reasonable and clear objectives and contents of tasks can better reduce the uncertainty in employees' minds. When employees know exactly what to do, how to do it and what the company expects of them, they will be motivated to work, and thus the pressure will be reduced naturally.

Second, treating employees fairly makes them feel good about themselves. Many scholars firmly believe that much of the pressure on employees stems from unfair treatment. For example, Wang Yufeng and Yang Duo (2014) point out that as the manager of the company, it is necessary to realize this, clarify the company's salary and performance appraisal system and promotion system, treat each employee fairly, provide the same development opportunity and space, and make employees feel the real fairness in their hearts, thus reducing the pressure 
on employees [26]. In addition, Muhammad, et al. (2018) also believe that managers should learn to motivate employees, praise their work results, and make employees self-affirmation, so that employees will be full of interest in the work they are engaged in, and the pressure will be transformed into motivation, therefore, they can take the initiative to complete the work with quality and quantity [27].

Third, the balance between family and work. Family and work as two relatively independent Spaces, A good balance between the two can promote each other, and vice versa. Therefore, in order to make employees work hard, managers should know about their families, care about their difficulties in life and solve their worries. Help employees solve problems in their families with their permission. For example, Dong Fei (2016) puts forward corresponding education should be carried out for employees to learn to balance the relationship between family and work independently, so as to avoid unnecessary losses of enterprises and employees [28].

Finally, cultivate good working habits of employees. Good work habits can get twice the result with half the effort. For example, if employees plan their work effectively, they can ensure that everything is under control as much as possible, so that the work can be completed efficiently without accumulation, thus reducing employees' irritability and anxiety. Employees have a clear idea of what they need to accomplish, and the pressure will be reduced.

\subsubsection{Countermeasure to Reduce Resistance}

Similarly, based on the analysis of the problem of employee resistance, this paper proposes four methods to reduce employee resistance. First of all, the company should implement educational communication negotiation for employees. On the one hand, through explanation to employees, they can understand the process of organizational change and the benefits brought by organizational change to the company. In addition, understand the reasons and concerns of employees against change, and explain the role of organizational change and its impact on enterprises and individuals. Let employees from the concept of the importance of organizational change, change can be carried out smoothly. On the other hand, employees' resistance to change can be reduced through negotiation, Negotiate with employees with things that employees are concerned about, such as the company's relevant welfare policies, bonuses, promotion opportunities, holidays, etc., so as to obtain employees' support for organizational change.

Second, companies should encourage employees to actively participate in organizational change. Encourage employees to participate in change, and be a change agent rather than a hindrance. Participation can strengthen employees' feelings. When employees oppose the change, it is because they do not know it, and they are not sure about the result of the change. If they experience it personally, they will have a deep understanding. When employees realize the importance of change, they can accept organizational change from the bottom of their 
heart and will not take actions that hinder change.

Third, manipulation should be used appropriately. Companies can reduce resistance to change by manipulating it in subtle ways or means. For example, by concealing or distorting facts, it is easy for employees to see the benefits of change, either in the most obvious places or by exaggerating the benefits. It can also reverse explain the harm brought to employees by hindering changes, so that employees can consciously support organizational changes.

Finally, companies can take enforcement measures if they have to. Use direct threats and force to threaten employees. For example, if you continue to block change by taking a pay cut or demotion, or by transferring jobs, the method is not to solicit the opinions of employees, but to force them to implement it. Organizations should use this approach sparingly because it can discourage employees from doing their jobs.

\section{Conclusion}

First of all, through literature review, it discusses the connotation of organizational change and organizational change, employees pressure and resistance against the background of research, and based on the research of predecessors, taking the Jing Yi network technology Co., Ltd. as an example to specifically analyze blocking problems appeared in the process of organizational change of Jing Yi. This paper discusses the source of employee pressure and resistance, and negative impact of employee stress and resistance on the organization, and through the analysis of the problem, put forward the solution of employee pressure and resistance solution.

\section{Research Findings and Future Research Direction}

If an enterprise can make good use of the pressure of employees and the employee resistance, pressure and an employee's resistance will not necessarily produce negative influence. Moreover, if done properly, the pressure and resistance of employees can be turned into motivation for organizational development. In addition, through the analysis of employee resistance and pressure, the defects and deficiencies in the process of organizational change can be seen. The improvement of the implementation process of organizational change by managers is not only beneficial to the development of enterprises, but also beneficial to the long-term development of employees. This paper takes Jing Yi Network Technology Co., Ltd. as an example to analyze the problem of employee pressure and employee resistance under the organizational change. It is carried out from the four aspects of organizational structure change, organizational personnel change, organizational technology change and organizational culture change. It is found that the pressure of employees under organizational change comes from four aspects: First, the pressure of staff under personnel reform, including the increase of company promotion space, a special promotion system, the pressure of organizational leadership style change, the change of tasks and work content caused by organizational change, and the change of organizational stability 
breaking the original organization; the second is the staff pressure under the enterprise organizational structure reform, including the staff pressure brought by the organizational strategy change, the staff pressure of the organizational management level and the staff pressure of the scope change; third, the pressure of employees under the technological change of the enterprise, including the improvement of employees' knowledge and skills and business ability, and the new familiarity of the working environment, working methods and office equipment; Fourth, the pressure of employees under the change of corporate culture. The causes of resistance mainly include uncertainty, habit change and the fact that organizational change is not in the best interests of the organization. The study also found that the impact of employee pressure and resistance on the development of the enterprise is mainly in four aspects: employees' negative work, increasing the difficulty of enterprise management, hindering the formulation of company policies and systems, and hindering the organization's integration of technology and resources. In addition, by analyzing employee pressure and resistance problems, this paper put forward the countermeasures and reduce the staff pressure and resistance respectively, including the staff consultation and formulate reasonable clear objectives, fair treatment of employees, let employees' self-esteem, and the balance of family and work to reduce employee stress method, and cultivate employees good work habits, company should implement education for staff communication negotiations, encourage employees to actively participate in, the company should use appropriate manipulation, companies should adopt compulsory measures to reduce employee resistance. Although this paper takes Jing Yi Network Technology Co., Ltd. as a case study to put forward effective opinions and methods for the organizational change of Jingyi network, this paper can also provide a reference frame for other enterprises with similar problems, so as to promote the effective solution of the pressure and resistance of employees in the organizational change. With the rapid development of economy, the enterprise in order to adapt to the change of economic environment at home and abroad, will need to be constantly on organizational change, organizational change inevitably involves the enterprise resources integration, and enterprise's human resources is the most important resource of enterprise, thus employees of enterprises in the process of organizational change in pressure and resistance analysis is particularly important. However, at present, there are many theoretical literatures in this field, while empirical studies are relatively scarce. In the future, some empirical studies in this field can be appropriately combined with cases.

\section{Acknowledgements}

Special thanks to the strong support of Jing Yi Network Technology Co., LTD.

\section{Conflicts of Interest}

The author declares no conflicts of interest regarding the publication of this paper. 


\section{References}

[1] Nigam, A., Huising, R. and Golden, B. (2016) Explaining the Selection of Routines for Change during Organizational Search. Administrative Science Quarterly, 4, 551-583. https://doi.org/10.1177/0001839216653712

[2] Chen, D. and Wang, C. (2015) The Influence of Employee Role Overload in the Context of Organizational Change: A Mediation Model with Mediation. Journal of Zhejiang University: Humanities and Social Sciences, 3, 140-157.

[3] Robbins, S.P. and Coulter, M.K. (2013) Management. Renmin University of China Press, Beijing.

[4] Gersick, C.J.G. (1991) Revolutionary Change Theories: A Multilevel Equilibrium Paradigm. Academy of Management Review, 16, 10-36. https://doi.org/10.5465/amr.1991.4278988

[5] Kahnall, C. (2015) Management of Organizational Change. 5th Edition, China Renmin University Press, Beijing.

[6] Lindell, M.K. and Drexler, J.A. (1979) Issues in Using Survey Methods for Measuring Organizational Change. Academy of Management Review, 4, 13-19. https://doi.org/10.5465/amr.1979.4289170

[7] Meng, F., Zhang, W., Yang, C. (2008) A Review of the Theory of Organizational Change in Western Enterprises. Journal of Beijing Jiaotong University (Social Sciences Edition), 1, 13-19.

[8] Zhang, Y. (2008) Employee Self-Performance Management that Drives Organizational Change. Human Resource Development of China, 6, 17-19.

[9] Di, Y. and Sun, D. (1998) The Main Obstacles and Sountermeasures to Realize the Smooth Transition of Enterprise Organizational Change. China Soft Science, 2, 90-93.

[10] Qi, Z. (2004).Five Major Obstacles to Organizational Change. Future and Development, 3, 50-52.

[11] Graetz, F. and Smith, A.C.T. (2010) Managing Organizational Change: A Philosophies of Change Approach. Journal of Change Management, 2, 135-154. https://doi.org/10.1080/14697011003795602

[12] Chen, Q. (2011) Dilemma of Organizational Change: Causes and Countermeasures-The View of Cultural Rigidity. Forum on Chinese Culture, 3, 163-168.

[13] Schwarz, G.M. and Stensaker, I.G. (2016) Showcasing Phenomenon-Driven Research on Organizational Change. Journalof Change Management, 4, 245-264. https://doi.org/10.1080/14697017.2016.1230931

[14] Liu, J. (2017) Analysis of the Impact of Economic Globalization on the Organizational Change of China's Enterprise Administration. Business Managers, 1, 127.

[15] Rolf, V.D., Valeria, C. and Shuang, L. (2018) Shared Identity in Organizational Stress and Change. Current Opinion in Psychology, 23, 20-25.

https://doi.org/10.1016/j.copsyc.2017.11.005

[16] Richardson, K.M. (2017) Managing Employee Stress and Wellness in the New Millennium. Journal of Occupational Health Psychology, 22, 423-428. https://doi.org/10.1037/ocp0000066

[17] Castillo, C., Fernandez, V. and Sallan, J.M. (2018) The Six Emotional Stages of Organizational Change. Journal of Organizational Change Management, 3, 468-493. https://doi.org/10.1108/JOCM-05-2016-0084

[18] American Project Management Association (2014) A Practical Guide to Organiza- 
tional Change Management. China Electric Power Press, Beijing.

[19] Zhang, J. and Duan, Y. (2013) Research on the Dynamic Mechanism of Market-oriented Organizational Change. Scientific Research Management, 10, 110-118.

[20] Zhang, J., Fan, Y. and Ji, X. (2013) Research on the Relationship between Organizational Change Factors and Employees' Reaction to Change. Management Review, 11, 50-65.

[21] Lin, Z., Zheng, S., Xia, F. and Meng, D. (2016) Formation Mechanism of Work Pressure in Organizational Change: Based on the Sample of State-Owned Enterprises Empirical Research. China Soft Science, 3, 85-95.

[22] Farrell, M. (2018) Leadership Reflections: Organizational Culture. Journal of Library Administration, 58, 861-872. https://doi.org/10.1080/01930826.2018.1516949

[23] Zhang, J., Fan, Y. and Zhang, X. (2016) Research on Emotional Arousal and Its Influencing Mechanism in Organizational Change. Management Review, 3, 126-140.

[24] Shi, G. (2019) Discussion on Enterprise Organizational Reform Strategy Based on Management Informatization. Enterprise Reform and Management Preceding, 2, 20-24.

[25] James, H. (2017) Disorders through Organizational Change. Drug and Alcohol Dependence, 171, e64. https://doi.org/10.1016/j.drugalcdep.2016.08.186

[26] Wang, Y. and Yang, D. (2014) Study on the Formation Mechanism and Stress Management of Organizational Change on Employees. Guizhou Social Sciences, 6, 94-99.

[27] Muhammad, A.R., Muhammad, M.K. and Bahaudin, G.M. (2018) The Impact of Organizational Change on Employee Turnover Intention: Does Stress Play a Mediating Role? Public Organization Review, 18, 313-327.

https://doi.org/10.1007/s11115-017-0380-8

[28] Dong, F. (2016) Analysis of the Resistance to Organizational Change and Countermeasures. Intelligent City, 8, 107-109. 